\title{
Periodontal disease and hypertension: a chicken and egg story?
}

\author{
Augustine N. Odilil ${ }^{\mathrm{a}, \mathrm{b}}$ and Jan A. Staessen ${ }^{\mathrm{b}, \mathrm{c}}$
}

Journal of Hypertension 2010, 28:2382-2383

${ }^{\text {aDDepartment }}$ Internal Medicine, College of Health Science, University of Abuja, Nigeria, ${ }^{b}$ Studies Coordinating Centre, Division of Hypertension and

Cardiovascular Rehabilitation, Department of Cardiovascular Diseases, University of Leuven, Leuven, Belgium and ' Department of Epidemiology, Maastricht University, Maastricht, the Netherlands

Correspondence to Jan A. Staessen, MD, PhD, FESC, FAHA, Studies Coordinating Centre, Laboratory of Hypertension, University of Leuven, Campus Sint Rafaël, Kapucijnenvoer 35, Block D, Box 7001, B-3000 Leuven, Belgium

Tel: +32 1634 7104; fax: +32 1634 7106;

e-mail: jan.staessen@med.kuleuven.be,ja.staessen@epid.unimaas.nl

See original paper on page 2386

Tsakos et al. [1], in this issue of the Journal of Hypertension, tried to find out whether periodontal inflammation is associated with raised blood pressure. They came up with the conclusion that gingival bleeding, a marker of current periodontal inflammation, was the only measure consistently and significantly associated with raised systolic blood pressure and an increased odds of hypertension in the US population throughout the adjustment process. Hypertension is largely unrecognized in many patients and produces significant organ damage before the diagnosis is made. It is also the predominant risk factor for all major cardiovascular diseases. Its control contributes significantly to reducing morbidity and mortality. Establishing an association between an easily recognizable and commonly prevalent condition [2], like periodontal disease, with a rather silent but damaging clinical condition like hypertension is an original research idea.

As plausible as the idea may seem, the design of the study by Tsakos et al. leaves important questions unanswered. Using a cross-sectional design to establish causality is the lowest form of scientific evidence, which can only be considered hypothesis generating. The authors could not strongly establish that the periodontal inflammation is the cause of the increased blood pressure, especially when they reported that the only measure of periodontal inflammation to have significant association with blood pressure is gingival bleeding. They cannot exclude reverse causality because hypertension in itself may lead to malfunction of small arterioles and may be responsible for gingival bleeding with or without periodontal inflammation. One may, thus, argue that gingival bleeding just like epistaxis [3] is reflecting target organ damage in hypertension.

The blood pressure values used in the study are averages of three readings recorded at a single medical examination, which also included the periodontal examination. The authors did not state the order of the procedures at the examination. If it was not standardized, participants having the gingival examination before the measurement of blood pressure might have had a larger white-coat effect. This might have inflated the association between blood pressure and gingival bleeding. The same argument has been raised concerning the presumed association between hypertension and epistaxis, as most studies $[3,4]$ reported that the blood pressure tended to normalize spontaneously, if checked on a later date, when the participants no longer have epistaxis. Moreover, blood pressure is characterized by large variability and the diagnosis of hypertension should be made on the basis of multiple blood pressure measurements taken on separate days as recommended by current hypertension guidelines [5,6]. This recommendation was not followed in this study.

According to the authors' hypothesis [1], periodontal disease is a potential source of high levels of cytokines and inflammatory makers, such as C-reactive protein (CRP). Inflammation, in turn, causes endothelial dysfunction and arteriolar bleeding. One would then expect that for periodontal inflammation to be associated with hypertension, the pathological process would involve raised CRP levels and that hypertension would be associated with chronic periodontal damage. Neither of these two conditions were met in the study by Tsakos et al., as an elevated blood pressure was rather associated with a marker of acute periodontal inflammation and with lower CRP levels.

Previous research linked periodontal disease with increased susceptibility to atherosclerosis and unfavorable cardiometabolic risk profile [7,8]. Treatment of periodontal disease potentially improves these conditions [9]. No studies have, however, clearly demonstrated that treatment of periodontal disease lowers blood pressure or conversely that blood pressure lowering improves periodontal disease. This might be the objective of further research. Future studies must be prospective and if possible randomized, for instance, as a substudy in a clinical trial of tight and usual blood pressure lowering. It would be interesting to test the effects, if any, of treatment of periodontal disease on the efficacy of antihypertensive drugs, or vice versa. Drugs potentially causing xerostomy, such as centrally acting agents, should be avoided in such experiments. In prospective studies of populations or patients with periodontal disease as a predefined outcome, relevant covariables should be 
measured. They include, for example, eating habits, tobacco usage (both quantity and method of administration), alcohol consumption and tooth hygiene. Nibali et al. [10] reported interaction between genetic polymorphism in the vitamin $\mathrm{D}$ receptor and cigarette smoking in relation to the presence and progression of periodontitis. Periodontal disease and subsequent tooth loss also may lead to poor dietary habits. Patients with these conditions are likely to favor soft carbohydrate foods [11] and restrict fibers [12] and vegetables [13]. These food habits influence a patient's usual blood pressure [14].

In conclusion, Tsakos et al. [1] raised an interesting hypothesis. If the observed association between hypertension and periodontal disease can be replicated, the question remains what is cause and consequence. Or perhaps both conditions might be linked to a common third factor like genetic predisposition. Only prospective studies or randomized experiments can generate a definite answer.

\section{References}

1 Tsakos G, Sabbah W, Hingorani AD, Netuveli G, Donos N, Watt RG, et al. Is periodontal inflammation associated with raised blood pressure? Evidence from a National US survey. J Hypertens 2010; 28:2386-2393.

2 Brown $\mathrm{L}$, Loe $\mathrm{H}$. Prevalence, extent, severity and progression of periodontal disease. Periodontol 2000 1993; 2:57-71.

3 Herkner H, Laggner AN, Mullner M, Formanek M, Bur A, Gamper G, et al. Hypertension in patients presenting with epistaxis. Ann Emerg Med 2000; $35: 126-130$
4 Herkner H, Havel C, Mullner M, Gamper G, Bur A, Temmel AF, et al. Active epistaxis at ED presentation is associated with arterial hypertension. Am J Emerg Med 2002; 20:92-95.

5 Mancia G, De Backer G, Dominiczak A, Cifkova R, Fagard R, Germano G, et al. 2007 guidelines for the management of arterial hypertension. The task force for the management of arterial hypertension of the European Society of Hypertension (ESH) and of the European Society of Cardiology (ESC). $J$ Hypertens 2007; 25:1105-1187.

6 Chobanian AV, Bakris GL, Black HR, Cushman WC, Green LA, Izzo JL Jr, et al. Seventh report of the Joint National Committee on Prevention, Detection and Evaluation, and Treatment of High Blood Pressure. Hypertension 2003; 42:1206-1252.

7 Pradeep AR, Hadge P, Arjun RP, Shetty SR, Shareef K, Guruprasad CN. Periodontitis as a risk factor for cerebrovascular accident: a casecontrol study in the Indian population. J Periodontal Res 2010; 45:223228.

8 Caplan DJ, Pankow JS, Cai J, Offenbacher S, Beck JD. The relationship between self-reported history of endodontic therapy and coronary heart disease in the Atherosclerosis Risk in Communities Study. J Am Dent Assoc 2009; 140:1004-1012.

9 Yao Z, Yang J, Pan L, Chen Z. Periodontal treatment: potential to reduce cardiovascular morbidity and/or mortality. Med Hypotheses 2009; 73:3335.

10 Nibali L, Parkar M, D'Aiuto F, Suvan JE, Brett PM, Griffiths GS, et al. Vitamin D receptor polymorphism (-1056 Taq-I) interacts with smoking for the presence and progression of periodontitis. J Clin Periodontol 2008; 35:561-567.

11 Johansson I, Tidehag P, Lundberg V, Hallmans G. Dental status, diet and cardiovascular risk factors in middle-aged people in Northern Sweden. Community Dent Oral Epidemiol 1994; 22:431-436.

12 Nowjak-Raymer RE, Sheiham A. Association of edentulism and diet and nutrition in US adults. J Dent Res 2003; 82:123-126.

13 Hung HC, Willett W, Ascherio A, Rosner BA, Rimm E, Joshipura KJ. Tooth loss and dietary intake. J Am Dent Assoc 2003; 134:1185-1192.

14 Appel LJ, Moore TJ, Obarzanek E, Vollmer WM, Svetkey LP, Sacks FM, et al. A clinical trial of the effects of dietary patterns on blood pressure. DASH Collaborative Research Group. N Engl J Med 1997; 336:11171124. 